Hispania Sacra, LX

122, julio-diciembre 2008, 659-681, ISSN: 0018-215-X

\title{
CONCURSOS ECLESIÁSTICOS COMO ESPACIOS DE EJERCICIO DE PODER. ESTUDIO DE CASO: LOS DE LA SEDE CORDOBESA ENTRE 1799 Y $1815^{*}$
}

POR

VALENTINA AYROLO

CONICET-UNMDP

\begin{abstract}
RESUMEN
El trabajo que presentamos constituye una propuesta de uso de los documentos relativos a concursos eclesiásticos de forma diferente a lo que usualmente se hace. Por eso centraremos el análisis en los expedientes de concursos, entre la colonia y la independencia, considerando sobre todo los contextos histórico general y el diocesano. Nuestra intención es servirnos de los datos que nos brindan los expedientes para explorar, no sólo los perfiles clericales, sino también el espacio diocesano en la complejidad que comportaba en tanto sede de poder eclesiástico.

PALABRAS ClAVE: Diócesis de Córdoba, clero, Concursos eclesiásticos, independencia, poder 1799 Y 1815

\section{ECCLESIASTICAL BIDDING PROCESSES AS SPACES WHERE POWER IS EXERCISED. CASE STUDY: THE BIDDING PROCESSES OF CÓRDOBA SEE BETWEEN 1799 AND 1815}

\begin{abstract}
This paper we are presenting introduces an alternative way to use documents related to ecclesiastical bidding processes in a way that is different from the usual one. We will focus on the analysis of bidding processes files, between colonial times and the independence, paying special attention to the general historical
\end{abstract}

\footnotetext{
* Este trabajo formaba parte del monográfico dirigido por su autora y editado en el número 122 de Hispania Sacra.
} 
context and the diocese's context. We aim at taking the information that the files provide to explore not only the clerical profiles, but also the diocese as a complex see of ecclesiastical power.

KEY WORDS: Diocese of Cordoba (Argentina), Clergy- Ecclesiastical bidding, independence, power 1799 AND 1815

Recibido/Received 11 enero 2008

Aceptado/Accepted 23 febrero 2008

Los estudios existentes a partir de los expedientes de concursos han servido en general, para conocer al clero contemplando principalmente sus perfiles: estudios, edades, orígenes, etc. Además, y sobre todo, estos trabajos han sido muy importantes para evaluar el impacto que estas prácticas tuvieron en la formación clerical tal como lo habían imaginado las decretales tridentinas ${ }^{1}$.

Según señala Manuel Riego tanto los concursos como las conferencias morales tuvieron gran importancia en la formación permanente del clero elevando su nivel cultural y favoreciendo «la virtud y el cumplimiento del ministerio sacerdotal y parroquial, ya que esto se valoraba en la elección de los candidatos» ${ }^{2}$.

A la luz de las reformas tridentinas no sólo el clero se convertirá en objeto de reforma, sino también las prácticas religiosas y los sacramentos que materializaban su intervención. En ese marco, el espacio parroquial comienza a cobrar un nuevo sentido y a presentarse como un lugar de mediación real entre la sociedad y la Iglesia tal como será definido, con más nitidez, recién a principios del siglo $\mathrm{XX}^{3}$.

Para la corona española, la necesidad de reformar la organización beneficial, propulsó los llamados a concurso y aunque no sabemos cómo se trasladó esta inquietud al sur de América podemos intuir que algún eco llegó. El hecho de que el primer obispo de la diócesis de Córdoba, creada en $1806^{4}$, el peninsular Rodrigo A. de Orellana se haya mostrado tan interesado en la modificación de

\footnotetext{
${ }^{1}$ Leandro Higueruela, «Los concursos a parroquias en la diócesis de Toledo durante el pontificado del Cardenal Borbón (1800-1823)», en Hispania Sacra, 27 (1974), pp. 237-283. Manuel M., RIEGO Los concursos a parroquias en la Archidiócesis de Sevilla (1611-1926). Córdoba - España, Caja-Sur, 1999. José, SARmiento PÉREZ «Concursos parroquiales de la diócesis de Badajoz en el episcopado de Mateo Delgado Moreno (1814, 1818, 1836)» Revista de estudios extremeños. Nº 3, 2003.

2 Manuel M., RIEGo Los concursos a parroquias... op. cit., p. 19.

${ }^{3}$ Milagro Gallardo «Las parroquias como espacio de mediación Iglesia y sociedad, Córdoba 1905-1925» Primeras Jornadas Nacionales de Historia Social, Córdoba, Argentina, La Falda, 2007.

${ }^{4}$ Recordamos que la diócesis del Tucumán (1570-1806) estaba conformada por las jurisdicciones de Salta, Jujuy, Tarija, Catamarca, La Rioja, Tucumán, Santiago del Estero y Córdoba. Al dividirse en 1806, el obispado de Córdoba quedo conformado por La Rioja, Córdoba y las tres provincias cuyanas (San Juan, San Luis y Mendoza) antes pertenecientes a la diócesis de Santiago de Chile.
}

Hispania Sacra, LX

122, julio-diciembre 2008, 659-681, ISSN: 0018-215-X 
la traza diocesana, nos podría estar hablado de ese interés, combinado a las necesidades locales propiamente dichas ${ }^{5}$.

La implementación de concursos para cubrir beneficios vacantes forma parte de los mecanismos puestos en marcha para ajustar el clero a un modelo más instruido, más alejado de las cosas del mundo, a la figura de un pastor y a la cura de almas. La tarea fue ardua y dificil la obtención de resultados en concordancia con los objetivos. Creemos que el solo hecho de presentarse a un concurso acercó a los eclesiásticos del Tucumán al modelo que se pretendía siguieran6. Como veremos, existe una relación estrecha entre el obispo que realizó cada llamado, la forma en que éstos fueron convocados y las expectativas que se depositaban en el clero.

A ritmo lento, las parroquias se fueron convirtiendo en espacios clave de la organización diocesana. De allí la importancia de los concursos en tanto mecanismos que permitían controlar la calidad de los párrocos que ocuparan esos espacios centrales del entramado diocesano ${ }^{7}$.

Este trabajo constituye una propuesta de uso de los documentos relativos a concursos eclesiásticos de forma diferente a la usual. Se centra el análisis en los expedientes existentes, entre la colonia y la independencia, considerando sobre todo los contextos histórico general y el diocesano ${ }^{8}$. Elegimos tres concursos. El primero es el de $1800^{9}$, convocado en 1799 por el obispo Mariano Moscoso para la «región diocesana» del Tucumán. El segundo, es de 1805 también convocado por Moscoso pero sustanciado después de su muerte. El último, es de 1814 emplazado por el cuestionado obispo Rodrigo A. de Orellana pero este, sólo atañe a la nueva diócesis de Córdoba.

A través de de los datos que brindan los expedientes queremos explorar no sólo los perfiles clericales, sino también el espacio diocesano en la complejidad que comportaba en tanto sede de poder eclesiástico.

\footnotetext{
5 Para ver el desarrollo español se puede consultar Hermann, Christian L'Eglise d'Espagne sous le patronage royal (1476-1834), Madrid, Biblioteca de la Casa de Velásquez, 1988, pp. 221-262.

${ }^{6}$ Cfr. Valentina AYrolo, «Entre los fieles y dios, hombres. Observaciones acerca del clero secular de la Diócesis de Córdoba en las primeras décadas del siglo XIX.» en Valentina AYrolo (comp.) Estudios sobre clero iberoamericano, entre la independencia y el Estado-Nación. Centro Promocional de las Investigaciones en Historia y Antropología (CEPIHA), Universidad Nacional de Salta, EUNsa, 2006.

${ }^{7}$ Concilio de Trento, sesión XXIV, canon 18 de reformatione.

8 Toda la información sobre los concurso esta en: Archivo del Arzobispado de Córdoba (AAC), Legajo 25 (1699-1859) «Concursos a Curatos y Oposiciones». Tres tomos. El ultimo concurso es de 1859 , sin embargo entre 1815 y 1859 no parecen haberse sustanciado concursos.

${ }^{9} \mathrm{El}$ anterior concurso es de 1793. Se presentaron treinta y cuatro candidatos y tuvo lugar en la Iglesia del Monserrat. Archivo del Arzobispado de Córdoba (AAC), Leg. 25, T.II.
} 
Examinaremos, por un lado la parte formal de los llamados, esto es, su estructura misma. Luego, realizaremos un rápido balance sobre los rasgos del clero riojano que se presentó a concursar ${ }^{10}$ a fin de tener una idea del perfil de una parte de los clérigos y por último observaremos algunos hechos acaecidos durante los concursos a fin de asomarnos a problemas vinculados sobre todo al ejercicio del poder.

\section{GENERALIDADES}

Como sabemos, cuando una parroquia o curato vacaba generalmente se utilizaban dos mecanismos para cubrirla. El primero era el llamado a concurso como lo indicaba Trento ${ }^{11}$, el segundo era el nombramiento en calidad de interino ${ }^{12}$, ambas formas fueron practicadas en la región eclesiástica del Tucumán ${ }^{13}$.

Si bien contamos con datos de concursos para el período colonial, no ocurre lo mismo con la etapa pos independentista donde la propia lógica y dinámica política fue marcando el ritmo de la vida diocesana ${ }^{14}$.

Por otra parte, y dado lo costoso del procedimiento, los llamados a concurso generalmente se realizaban cuando así lo justificaba un número interesante de

${ }^{10}$ Elegimos al grupo de los riojanos por dos motivos. Primeramente porque no pertenece a la élite de la sede episcopal, por ende es un grupo subsidiario de ésta. Por otro, por ser el único grupo con estas características que puede ser analizado en los tres concursos ya que siguió formando parte de la diócesis de Córdoba en 1806 luego de la división del de Tucumán.

${ }^{11}$ Sesión XXIV, canon 18 De reformatione.

12 El Concilio de Trento autorizaba al obispo a realizar una selección secreta del candidato a cubrir una vacante si «las rentas de la expresada parroquia fuesen tan cortas, que no merezcan el trabajo de este examen, o no haya persona que quiera sujetarse a él, por las manifiestas parcialidades, o facciones que haya...» puede que esta selección haya sido solo del obispo sin mediar el procedimiento sugerido por el tridentino de convocar un tribunal etc. El sacrosanto y ecuménico concilio de Trento, Sesión XXIV, Cap. XVIII, p. 437-1438. A veces lo exiguo de las rentas de una parroquia no alentaban ni al llamado a concurso, ni a la presentación de candidatos por lo que se optaba por no llamarlo. Según Pilar García Jordán esta sería la explicación más conveniente para entender la gran cantidad de curas interinos en el Perú. Pilar García Jordán, P. Iglesia y poder en el Perú contemporáneo 1821-1919. Cuzco, Centro de Estudios Andinos «Bartolomé de las Casa, 1991.

13 «La región eclesiástica del Tucumán está conformada por las diócesis de Salta y Córdoba y el recorte temporal que la explica nos sitúa entre los años de la pos-independencia y los 40 del siglo XIX. En la conformación de la región el origen común, juega un rol importante dando coherencia al todo y permitiendo que la región pueda ser definida en términos histórico-culturales» Valentina AYROLO «Historia regional comparada ¿una nueva posibilidad analítica?» en Sara MATA DE LÓPEZ-Nidia ARECES (coord.) Historia Regional. Estudios de casos y reflexiones teóricas. Salta, EDUNSa. /CEPIHA, 2006, p. 110 .

${ }^{14}$ Cabe señalar que en España se siguieron efectuando concursos hasta 1962. Manuel M., RIEGO Los concursos a parroquias... op. cit.

Hispania Sacra, LX

122, julio-diciembre 2008, 659-681, ISSN: 0018-215-X 
parroquias vacantes. Por ello no era raro que muchas veces los administradores curiales nombraran a los párrocos de forma interina. Luego de 1815, como consecuencia de las dificultades de orden político la práctica más usual fue el nombramiento de clérigos para cubrir beneficios en todas sus categorías por parte de los Vicarios diocesanos, y muchas veces directamente por los administradores políticos de turno que ejercían el Patronato ${ }^{15}$.

Los llamados eran aprovechados también, para realizar modificaciones en las trazas diocesanas y en muchos casos, estos trámites demoraban la sustanciación de los exámenes. En el Tucumán, lo usual era dar cinco meses entre la publicidad del edicto y la sustanciación del concurso pero, por motivos diversos, en general se prorrogaban.

En lo formal, los concursos se publicitaban por medio de un edicto que se anunciaba en las diversas iglesias de la diócesis. Con un texto siempre similar se convocaba a:

A todas las personas a quienes lo infrascrito toca (...) en este Edicto (...) Hacemos saber que en esta nuestra Diócesis se hallan vacantes el curato (...)Y por quanto conviene al servicio de Dios y el Rey proveer estos beneficios en propiedad para el mejor desempeño de las obligaciones y funciones del Ministerio parroquial y bien espiritual de los feligreses, conforme a lo prevenido por el santo Concilio de Trento, y Leyes del real Patronato, hemos resuelto por Auto de este día, que se libren, publiquen y fixen edictos para la provisión de los expresados Beneficios, sus resultas, y de los que puedan vacar, así curados como simples, durante el presente Concurso (...) ${ }^{16}$.

Comúnmente los llamados eran abiertos a fin de comprender no sólo las parroquias indicadas en la convocatoria, sino además para aquellos que «puedan vacar asi curados, como simples, durante el presente concurso» ${ }^{17}$.

Las indicaciones para los postulantes eran las siguientes:

... a todos los eclesiasticos, que quieran hacer esta opocicion, y deberán tener entendido, que hande presentar los documentos, que califiquen la filiacion legitima, meritos, y servicios de cada uno; y que asi mismo hande ser examinados con exactitud, para poder formar el debido concepto de la instruccion, y suficiencia, qe tengan para el grave cargo de Parrocos, u Pastores de Almas» ${ }^{18}$.

\footnotetext{
${ }^{15}$ Algunos ejemplos de esto en AAC, Lég 25, t.III; Archivo del Cabildo Eclesiástico de Córdoba (ACEC), Legajos del Cabildo 110-119 y Lég. 26. Sobre el particular se puede consultar: Valentina AYROLo Funcionarios de Dios y de la Republica. Clero y política en las autonomías provinciales. Buenos Aires, BIBLOS, 2007.

${ }^{16}$ AAC, Leg, 25, t. III (1801-1859).

${ }^{17}$ Edicto del llamado de 1799, AAC, Lég. 25, t III

${ }^{18}$ Idem.
} 
Muchas veces en las presentaciones de meritos se agregaba la opinión de exprofesores que acreditaban la calidad del demandante y en algunos casos se iniciaban averiguaciones secretas, informes reservados, que podían derivar, como en uno de los casos que veremos, en el interdicción de presentarse a los exámenes ${ }^{19}$.

Los aspirantes debían especificar, en cada caso, para qué cargos se postulaban. Pese a ello y al resto de las cláusulas que debían respetarse, los expedientes de presentación que se conservan son muy desparejos. Los postulantes foráneos presentan legajos muy completos y se ajustan a la normativa vigente. Por el contrario, las presentaciones de clérigos locales son escuetas y uno diría que eran suficientes sus nombres y sus apellidos para que fuera aceptada la postulación.

Según sabemos desde 1784, para los llamados a concurso debía seguirse el modelo del Arzobispado de Toledo que había sido recomendado por Carlos III ${ }^{20}$. No obstante, como acabamos de señalar, en los llamados analizados, y suponemos que igualmente habrá sido antes ya que era lo usual seguir la costumbre más que las normas, notamos algunas licencias respecto a las recomendaciones reales. Respetando lo estipulado por Trento, o el azar y las propias condiciones diocesanas, en vez de nueve examinadores sinodales, normalmente hubo cinco ${ }^{21}$, salvo en 1814 que sólo se contó con tres ${ }^{22}$.

Otra adaptación fue la corrección y comunicación de los resultados. En el Tucumán no se calificaban los exámenes como por ejemplo en Sevilla, sobre 35 puntos máximos, sino que únicamente se aprobaba o desaprobaba por medio de una leyenda que decía por ejemplo: «Hoy 2 de marzo de 1805 habiendose leido esta platica, y resolucion, fueron aprovadas por todos los examinadores sinodales. Lo certifico Narciso Moyano (Secretario)» ${ }^{23} \mathrm{o}$ «La Plática y la resolución de casos antecedentes se leyeron el 10 de enero de 1815 en presencia de su

\footnotetext{
${ }_{19}$ Para el caso en cuestión sólo contamos con el expediente que tiene el descargo de la familia del interesado pero no sabemos nada del informante y tampoco tenemos el veredicto del Obispo, aunque al no estar Luna /Herrera en las listas de concurso, podríamos pensar que le fue negado el acceso.

${ }^{20}$ Cf. Manuel M., RIEGo Los concursos a parroquias... op. cit y Christian HermanN, L'Eglise d'Espagne sous le patronage... op. cit. p. 278.

${ }^{21}$ En 1800 los examinadores sinodales fueron cinco: Arzediano y Provisor del Obispado: Dr.n. Gregorio Funes, Magistral Dr.n. Juan Justo Rodríguez, R. Pe. Prior Fr. Domingo Leiva, R. Pe. Rector del la Univera ${ }^{d}$ Fr. Pedro José Suliván y Rector del Coleg.o Semino ${ }^{\circ}$ Dn. Leopoldo Allende.

22 Aunque el Concilio de Trento exigió tres examinadores como mínimo: «cuando haya alguna vacante de iglesia, cualquiera que sea, elija el Obispo tres de ellos que le acompañen en el examen; y ocurriendo después otra vacante, elija entre los seis mencionados o los mismos tres antecedentes, o los otros tres, según le pareciere. Sean empero estos examinadores maestros, o doctores, o licenciados en teología, o en derecho canónico, u otros clérigos o regulares, aun de las órdenes mendicantes, o también seglares, los que parecieren más idóneos; y todos juren sobre los santos Evangelios, que cumplirán fielmente con su encargo, sin respeto a ningún afecto, o pasión humana» Sesión XXIV, canon 18 de reformatione.
}

${ }^{23}$ Nota que figura al final del examen del Dr. José Gabriel Ocampo, AAC, Lég. 24, t IV-1805.

Hispania Sacra, LX

122, julio-diciembre 2008, 659-681, ISSN: 0018-215-X 
S.S I., y de los Examinadores Sinodales: quienes uniformem ${ }^{\text {te }}$ las aprobaron. Lo certifico en Córdoba dho dia, mes y año José Gabriel Vazquez secretario» ${ }^{24}$.

El día del concurso debían presentarse en el colegio Montserrat a la hora prescrita, que, en el primer caso fue a las 9 de la mañana, en el segundo a las 10 de la mañana y en 1814 a las $7.30 \mathrm{hs,} \mathrm{con} \mathrm{su} \mathrm{recado} \mathrm{de} \mathrm{escribir} \mathrm{y} \mathrm{misal.} \mathrm{Se} \mathrm{les}$ daba entre una hora y media y dos horas y media para resolver los «casos y dudas» para cuyas respuestas se debía apelar al derecho canónico y a la teología moral, como lo prescribía la Bula de Benedicto XIV de $1742^{25}$. Luego se les proponía un evangelio sobre el que tenían que «deducir» una plática. La resolución del primer ejercicio era en base a una situación ficticia sobre la que luego se realizan cuatro preguntas.

Citamos un ejemplo, el de los «Casos y dudas de Teología Moral, que se proponen $\mathrm{p}^{\mathrm{a}}$ el examen a los opositores a los Curatos vacantes en el concurso que celebra el IImo Sr Dr Dn Ángel Mariano Moscoso Dignísimo Obispo de esta Diócesis mi $\mathrm{Sr}_{\mathrm{r}}$ y los que se examinen darian alo menos apuntaran la razón delo que afirmen, o nieguen (...) se dictaron a los opositores... el día de hoy a las 9 de la mañana... 24 de agosto de $1800^{26}$ :

Sobre el 1er punto; ¿Si puede el párroco $\mathrm{p}^{\mathrm{r}}$ su jurisdiccion ordinaria o por pribilegio exponer a su feligresia $\mathrm{p}^{\mathrm{r}}$ confesor al sacerdote aprobado qe se halla sin licencia del Diocesano, y si podra autorizarlo paraqe lo confiese a el mismo?

Sobre el $2^{\circ}$ punto, ¿Si en el caso propuesto esta vedado al cura el comercio, y baxo de que penas; quales sean las especiales en Indias, y si cometió usura?

Sobre el tercer punto, ¿Si el matrimonio del caso es clandestino; o nulo por otro impedimento? Expongase.

Sobre el $4^{\circ}$ punto, Quales sean las causas, que excusen de rezar el oficio Divino ; si las del caso en este punto son suficientes, y no siendolo, desde que tiempo estará obligado el Parroco a restituir los frutos, y que parte?

El Evangelio que asigna es el capitulo 6 de $\mathrm{S}^{\mathrm{n}}$ Mateo que se halla en la Domminica 14 post Pentecostés» [Jesús a sus discípulos: Nadie puede servir a dos señores: porque, o aborrecerá al uno, y amará al otro o al uno sufrirá, y al otro despreciará]

Como se puede inferir de las preguntas que citamos, en general los casos y dudas hacían alusión a diversos aspectos de la confesión, solicitación, absolu-

\footnotetext{
${ }^{24}$ Nota que figura al final del examen del Dr. Joseph Ramón Alvarez, AAC, Lég. 24, t IV -1815

25 «... se propone por escrito à los opositores un caso con varias dudas sobre teología moral, para que sentasen su resolución bajo su firma, asignándoles al mismo tiempo un evangelio del que dedujesen un punto de doctrina, o formasen por maior a cerca de su contesto una plática moral con sencillez y claridad; y que por experiencia de los dos anteriores concursos [para confesar y predicar] se hallan acreditados los buenos efectos de este método» AAC, Lég. 52.

${ }^{26}$ Se llama a concurso para cubrir los beneficios vacantes: Rectoral de la Catedral, Rectoral de la Rioja, Una sacristía mayor, Curatos (rurales) Río Segundo (jurisdicción de Córdoba), del Alto (jurisdicción de Catamarca), Humahuaca (jurisdicción de Jujuy), Tulumba (jurisdicción de Córdoba), Río Negro (jurisdicción de Jujuy) y Calchaqui (jurisdicción de Salta), AAC, Leg. 25, T. III.
} 
ción de pecados de diverso grado, de la celebración y consumación del matrimonio, averiguación de libertad, grado de afinidad, y dispensas, a los sacramentos de la muerte: confesión, extrema unción y viático.Por último era objeto de examen la conducta de los clérigos ligada al ejercicio de actividades vedadas para ellos como el comercio, o a prácticas como el ayuno.

El idioma de los exámenes analizados, es principalmente el castellano, salvo el de 1814 que fue dictado en latín y las respuestas están en castellano con largos párrafos en un latín acriollado.

Como vemos, para alcanzar los concursos había que demostrar un cierto grado de capacitación y solvencia. Por ello el paso por la Universidad se hacía imprescindible. Concluidas y corregidas las pruebas se formaban las ternas precedidas por el candidato elegido por el obispo para cubrir cada curato ${ }^{27}$. De acuerdo con un documento de principios de siglo, el origen de las facultades de conformar las ternas procedía de una delegación que hacía el Patrono -en este caso el rey- en las autoridades eclesiásticas y no del derecho canónico ${ }^{28}$. Este mecanismo estaba consignado en el código de Indias (ley. 24 t. 6 y Lib.1) que ordenaba «los arzobispos ú obispos elijan, de los examinados y aprobados, tres de los que conceptúen más dignos, y pasen la terna al virrey presidente ó gobernador, (...) para que de ellos el virrey (...) presente al arzobispo ú obispo el que creyere más a propósito» 29 . Una vez confeccionada la terna, se presentaba al vicepatrón (el virrey, gobernador o capitán general, según el caso) quien elegía a la persona más conveniente de acuerdo su criterio. Usualmente coincidía con el primer candidato de la lista. Una vez realizada la selección; el obispo o el provisor le otorgaba la propiedad del cargo por la colación y entrega del beneficio.

Antes de pasar a la historia de los concursos me parece interesante detener la mirada fugazmente en este punto ya que consideramos que la forma de los concursos estuvo influida por el perfil de los dos obispos que los convocaron.

27 Por medio de la Real orden de 1 de septiembre de 1753 se establecieron las exigencias elementales para la redacción de ternas. La Carta Circular de la Cámara de Castilla de 9 de octubre de 1753 precisó, que éstas debían mencionar los grados, méritos y cualidades de cada uno de los tres sujetos clasificados. Christian Hermann, L'Eglise d'Espagne sous le patronage ... op. cit. pp. 263-270.

28 «Las facultades con que proceden los Ilmos Sres. obispos, cabildos en sede vacante, o sus deputados en las Iglesias del real Patronato que forman nóminas en los concursos no provienen de la curiosidad eclesiástica, ni se gobiernan por los sagrados cánones, sino de la del real Patronato, dimanada de la comisión del Príncipe, y sujeta a los derechos de aquel. [no pudiendo hacer ellos la elección de los curas como lo hacen de los obispos y canónigos] «... tomaron como prudente, y christiano arbitrio supuestos los concursos conformes al Sto. Concilio de Trento de encargar a los Ilmos. obispos, y cabildos en sede vacantes para que por sí, o sus diputados elijan de los examinados los tres idóneos y los propongan.» Instituto de Estudios Americanistas (IEA), rollo n ${ }^{\circ} 14$, doc. n 3090, en AAC.

${ }^{29}$ Los usos en los casos de concurso (según la Ley 24, titulo 6, libro 1 del Código de Indias) y las de vacancias sin concurso están descriptas en Justo DONOSO Instituciones del derecho canónico americano. Paris, Rosa y Bouret, 1858/1868, T. I.

Hispania Sacra, LX

122, julio-diciembre 2008, 659-681, ISSN: 0018-215-X 
Los dos primeros concursos (1799-1800 y 1804-1805) fueron citados por el obispo arequipeño Ángel Mariano Moscoso quien había iniciado su carrera como secretario de cámara de su tío el obispo de Santa Cruz, Fernando Pérez Oblitas, pero había ejercido el sacerdocio por espacio de treinta años en la parroquia rural de Tarata departamento de Tacna, Perú. Alejado entonces del mundo académico y citadino, sus expectativas tal vez hayan sido menores que las de su sucesor Rodrigo Antonio de Orellana. Este último, integrante de la orden premostratense, era maestro y Doctor en teología, examinador sinodal, regente de estudios en la Universidad de Valladolid, examinador de latinidad. Había dictado cursos de física experimental, también fue individuo honorario de la academia de «matemáticas y nobles artes», censor para la oposición a la cátedra de escrituras, teología moral, instituciones teológicas y miembro honorario de la Real Academia de jurisprudencia práctica de la Universidad. Al momento de su nombramiento para la diócesis de Córdoba del Tucumán ejercía como ministros general de la orden premostratense de toda la Península ${ }^{30}$. Parece plausible pensar entonces, que este ministro haya tenido una mirada diferente acerca de los que debía ser una diócesis que recién se había creado y de la que el era el primer obispo. Esperanzas que se adivinan en la forma de idear su diócesis y los sacerdotes que debían servirla.

Pero yendo directamente a la historia de los tres llamados que analizaremos podemos decir brevemente que todos sufrieron demoras por causas diversas. Así paso por ejemplo en 1800. La fecha establecida por el edicto de enero de 1799 fue aplazada en dos ocasiones. La primera porque llegado el momento, en junio de 1799 , el virrey y vice-patrono no se había expedido en relación a la división de los curatos de Río Segundo y Calchaqui, pedidos por el obispo Ángel M. Moscoso ${ }^{31}$. Una nueva dilación, a causa de una indisposición del obispo reprograma el examen para finales del año 1799. Llegado el momento se produce un nuevo retraso con lo cual el concurso se sustancia un año después de lo previsto:

... no pudiendo asimismo hacerlo a principios del año venidero, asi por la estacion de calores, y lluvias, en que se ponen intransitables los Rios, como por acercarsela (sic) la Quaresma en que es indispensable la asistencia de los Curas en sus Parroquias la de sus Tenientes, y otros Sacerdotes, que les ayuden a doctrinar, predicar y desobligar a sus feligreses de los preceptos de confesion y comunion: Por tanto: impelido de estas consideraciones, hemos determinado prorrogar, como en efecto prorrogamos, el termi-

\footnotetext{
30 Todos los datos fueron tomados de Américo A. TonDa El obispo Orellana y la Revolución. Córdoba, Junta Provincial de Historia de Córdoba, 1981, pp. 18-23.

${ }^{31}$ Pasados los 5 meses del llamado que había sido realizado en enero de 1799, el obispo Moscoso, informa que antes de sustanciar el concurso hay que consultar al vice- patrón (el virrey) acerca del asunto de la división de curatos, por eso prorrogan 4 meses el término del edicto de convocatoria. AAC, Leg. 25, T. IV.
} 
no de los Edictos hta. el veinte, y sinco de junio del año siguiente dias despues de la octava de Corpus a que se extiende regular. ${ }^{\text {te }}$ el cumplimiento del precepto anual en algunos Curatos (...) ${ }^{32}$.

Los edictos del concurso de 1805 se fijaron en la catedral a fines de julio de 1804. La muerte de Moscoso ocurrida en el 3 de octubre de 1804, prorrogó el examen hasta marzo de $1805^{33}$. Pero también el último concurso que analizamos tuvo un derrotero irregular. Pese a que los objetivos del obispo Orellana habían sido desde el inicio normalizar la situación de la flamante diócesis, instituyendo nuevas parroquias y dividiendo más de una que encontraba muy extensa, los avatares políticos pospusieron su concreción ${ }^{34}$. El concurso fue convocado desde Tulumba, donde el obispo estaba de visita, 30 de enero de 1814. Junto al edicto, Orellana realizaba un pedido de división del curato rectoral de San Juan ${ }^{35}$. Las oposiciones tuvieron lugar en diciembre de $1814^{36} \mathrm{y}$ enero de 1815 Orellana fue expulsado por el gobierno central, definitivamente de su diócesis ${ }^{37}$.

\section{EXPLORANDO LEGAJOS: EL CASO DE LOS RIOJANOS}

A continuación presentaremos ejemplos de expedientes de concursos ciñéndonos sólo a los ejemplos de los clérigos riojanos que se presentaron en los tres

${ }^{32}$ Leg. 25, T. IV

${ }^{33}$ En 1805 los examinadores sinodales fueron: Cura Rector más antiguo Dr DN José Tristán, Cura Rector, su Compañero (sic), Dr. Dn. Pedro Bazán, $R^{\text {do }}$ Pe Prior del Convento de Predicadores Fray José Domingo Leiva, Dr. Dn. Miguel Castro Cura y Vicario del Beneficio de Punilla y el Pe jubilado Fray Elias Pereyra del Conv to de $\mathrm{S}^{\mathrm{n}}$ Francisco

${ }^{34} \mathrm{El}$ primer curato que pretende dividir es el de la propia ciudad de Córdoba, ya que esta contaba con una sola parroquia la de la Catedral. Sin embargo, y pese a sus esfuerzos esto no se realizará. El expediente y los estudios realizados a tal fin están en AAC, Leg. 25, T. IV.

35 Vale la pena señalar que en 1810, el obispo Orellana tuvo la intención de dividir el rectoral de la ciudad de Córdoba que funcionaba en la catedral por ser la única parroquia de la ciudad, pero su idea no prosperó, aunque había realizado las averiguaciones del caso. Cf. AAC, Leg. 25, T. IV.

${ }^{36}$ Los examinadores sinodales en 1814 fueron: Canónigo de Merced Gregorio José Gómez, RP Maestro Fray Domingo Leyba y RP Lector jubilado Fray Pantaleón García.

${ }^{37}$ Por haber participado de la resistencia organizada en Córdoba a la Revolución de 1810, el obispo Orellana fue puesto prisionero y su diócesis declarada vacante por las nuevas autoridades. En 1812 Orellana fue puesto en libertad y en 1813 volvió a Córdoba. Pese a haber obtenido la «ciudadanía de las Provincias Unidas»sigui siendo sospechado de antipatriota. En el año 1815, Orellana es nuevamente desterrado. Esta vez, a pedido suyo, al Convento de San Carlos en la provincia de Santa Fe. En 1817 es nombrado por la Corona española para ocupar el Obispado de Ávila ocasión en la cuál el gobierno de Buenos Aires lo manda a llamar. Temiendo las consecuencias, Orellana escapa hacia el Brasil, en el año 1818, desde donde escribe una carta al papa Pío VII informando el estado de cosas de la Iglesia en las Provincias Unidas. Para luego embarcarse hacia España. Cf. Valentina AYroLo «Una nueva lectura de los informes de la misión Muzi: La Santa Sede y la Iglesia de las Provincias Unidas» Boletín del Instituto de Historia Argentina y Americana «Dr. Emilio Ravignani» (UBA), No 14, 3era. serie, 2do. semestre de 1996, ISSN: 0524-9767, pp. 31-60. Américo Tonda El obispo Orellana .... op. cit.

Hispania Sacra, LX

122, julio-diciembre 2008, 659-681, ISSN: 0018-215-X 
llamados que estudiamos en este trabajo. La elección de los riojanos responde a dos causas. Primero, porque nos interesaba ver un grupo que no pertenece directamente a la elite de la sede episcopal, aunque sea subsidiario de ésta. Por otro, tomar a los riojanos resultaba interesante porque es el único grupo con estas características, que puede ser analizado en los tres concursos ya que perteneció a la diócesis de Tucumán y al momento de la división, en 1806, conformó la nueva diócesis de Córdoba.

Tomando en consideración los 23 clérigos que aparecen en la lista de eclesiásticos existentes en la Rioja en $1806^{38}$ sólo 5 de entre ellos, se presentan a los exámenes de los años 1800-1805 y 1814. Algunos de los nueve clérigos que examinaremos, pese a ser originarios de La Rioja cumplían funciones en otras jurisdicciones al momento del llamado. Es el caso de Pedro Ignacio Arze quien se desempeñaba en el rectoral de Catamarca, o de José Gabriel de Ocampo, quien ejercía la cura de almas en calidad de excusador, en la parroquia de Anacasti, jurisdicción de Catamarca.

Tabla I: «Lista de postulantes riojanos a los concursos de 1800, 1805 y 1814 según figuran en las listas» 39

\begin{tabular}{|l|c|c|c|}
\hline Nombre y Grado académico & $\mathbf{1 8 0 0}$ & $\mathbf{1 8 0 5}$ & $\mathbf{1 8 1 4}$ \\
\hline Dr. José Ramón Albarez & M-E & $\mathbf{E}$ & $\mathbf{E}$ \\
\hline Mxo. Pedro Ignacio Arze & M-E & & \\
\hline Mxo. Julián Carmona & $\mathbf{M}$ & & \\
\hline Mxo. Nicolás Carmona & M-E & & \\
\hline Dr. Fermín Aurelio de la Colina & & & $\mathbf{E}$ \\
\hline Dr. Pedro Antonio de la Colina & M-E & & \\
\hline Mxo. Manuel Herrera & M & M-E & E \\
\hline Dr. José Gabriel Ocampo & M-E & M-E & \\
\hline Mxo. José Patricio Tagle & M-E & & \\
\hline
\end{tabular}

Referencias: Están los exámenes: E / Están sus meritos y servicios: M

De una nómina de cincuenta y cinco inscriptos para el llamado de 1799, ocho riojanos se anotaron y siete se presentaron efectivamente a los exámenes. Para el concurso de 1805, hay 26 inscriptos y sólo tres son riojanos. En 1815,

\footnotetext{
38 AAC, Lég. 20, t. II.

39 AAC, Leg. 25, Tomos III y IV.
} 
de los 36 candidatos que se presentan a las pruebas, únicamente tres son oriundos de la Rioja.

Si miramos sus perfiles,podemos llegar a algunas conclusiones interesantes. La primera cosa a observar es que el grupo es bastante heterogéneo dado que para un promedio de edad de 33 años (mediana $=31$ años), el desvío estándar del mismo es de 10 años. La mayoría de los concursantes se presentó para la oposición de 1800 y entre ellos dos eran marcadamente mayores que el resto, Pedro Ignacio Arce con 57 años y Nicolás Carmona con 40 años. Dentro del grupo que concurrió al Monserrat en 1800, los tres más jóvenes, José Ramón Álvarez (25 años), Manuel F. Herrera (27 años) y José Gabriel Ocampo (31 años) se vuelven a presentar en 1805. Sólo este último -quien en el momento de su presentación ejercía funciones de cura excusador y vicario pedáneo de Ancasti (Catamarca) logró obtener el primer puesto en la terna para la silla del rectoral de Catamarca ${ }^{40}$. El más joven de los tres se presentó nuevamente en 1805 y 181441 .

Respecto de Manuel F. Herrera sabemos que se desempeño como maestro de primeras letras en ciudad de La Rioja y que en 1800 se actuaba como cura interino del curato de Piedra Blanca (San Luis). En 1806 figura como cura y vicario propietario de Guandacol puesto que posiblemente haya obtenido luego del concurso de 1800 o 1805.

El único que se presenta por primera vez en 1814 es Fermín A. de la Colina sobrino carnal de Pedro Antonio, y es lógico que no aparezca en el resto de las convocatorias ya que según sabemos, en 1813 recién obtuvo las órdenes menores ${ }^{42}$.

Respecto a la formación de los riojanos, podemos decir que todos habían pasado por las aulas de la Universidad de Córdoba, y algunos por las del Colegio Seminario de Loreto. La mayoría había obtenido un titulo de maestro en artes (filosofía), dos eran doctores en Teología y sólo uno, Pedro Antonio de la Colina, tenía ambos títulos.

Acerca de a la calidad de su ordenación, nos faltan datos para Fermín de la Colina y Pedro Ignacio Arze, pero del resto sabemos lo siguiente.

\footnotetext{
40 AAC, Leg. 25, III.

${ }^{41}$ José Ramón Álvarez, figura en la lista adjunta de 1806 como cura interino de Arauco (La Rioja), sin embrago no sabemos en que momento accedió a dicha parroquia.

${ }^{42}$ No tenemos otro registro sobre la ordenación de Fermín de la Colina, por lo tanto no sabemos si en 1815 ya había obtenido las órdenes mayores. AAC, Leg. 25, IV. Nos referiremos a este tema más adelante.

Hispania Sacra, LX

122, julio-diciembre 2008, 659-681, ISSN: 0018-215-X
} 
Tabla II: «Lista de los títulos de ordenación y años de la misma de los postulantes riojanos a los concursos de 1800,1805 y $1814 »^{43}$

\begin{tabular}{|l|l|}
\hline Nombre y Apellido & Titulo de ordenación y año \\
\hline Dr. José Ramón Albarez & $1799-$ Pasante del Colegio Seminario \\
\hline Mxo. Pedro Ignacio Arze & $1767---------------$ \\
\hline Mxo. Julián Carmona & $1800-$ Capellanía \\
\hline Mxo. Nicolás Carmona & $1782-$ Ayudante del Rectoral de La Rioja \\
\hline Dr. Fermín Aurelio de la Colina & $1813-$ Ordenes menores \\
\hline Dr. Pedro Antonio de la Colina & 1791 - Patrimonio \\
\hline Mxo. Manuel F. Herrera & $1796-$ Teniente de cura \\
\hline Dr. José Gabriel Ocampo & $1794-$ Ayudante de Cura \\
\hline Mxo. José Patricio Tagle & 1792 - Patrimonio \\
\hline
\end{tabular}

Las actividades que desarrollaban al momento de su presentación a concurso pueden explicar el posicionamiento en las ternas y sus recorridos de vida, ya que alguna experiencia previa en la administración parroquial era preferida.

\section{Tabla III: «Lista de los cargos que detentaban al momento de su presenta- ción a concurso» 44}

\begin{tabular}{|l|l|c|}
\hline Nombre y Apellido & Cargo & Año \\
\hline Dr. José Ramón Albarez & Pasante del Colegio Seminario & 1800 \\
\hline Mxo. Pedro Ignacio Arze & $\begin{array}{l}\text { Cura párroco de la matriz de Catamarca. Juez de } \\
\text { diezmos de la ciudad y partido de Catamarca }\end{array}$ & 1800 \\
\hline Mxo. Julián Carmona & Servicios a la Catedral de Córdoba & 1800 \\
\hline Mxo. Nicolás Carmona* & $\begin{array}{l}\text { Capellán interino del colegio de huérfanas de la } \\
\text { ciudad de la Rioja }\end{array}$ & 1800 \\
\hline $\begin{array}{l}\text { Dr. Fermín Aurelio de } \\
\text { la Colina }\end{array}$ & $\begin{array}{l}\text { Catedrático de Filosofía en la Iglesia rectoral de } \\
\text { La Rioja }\end{array}$ & 1815 \\
\hline $\begin{array}{l}\text { Dr. Pedro Antonio de } \\
\text { la Colina }\end{array}$ & Cura Vicario de la doctrina de Arauco (la Rioja) & 1800 \\
\hline Mxo. Manuel F. Herrera & $\begin{array}{l}\text { Teniente de Cura del Valle de Piedra Blanca (San Luis- } \\
\text { Obispado de Sgo. de Chile) } \\
\text { Cura Vicario propietario de Guandacol (la Rioja) }\end{array}$ & 1800 \\
\hline Dr. José Gabriel Ocampo & $\begin{array}{l}\text { Cura excusador y Vicario de Ancasti (Catamarca) } \\
\text { Cura y Vicario de Tinogasta (Catamarca) }\end{array}$ & 1805 \\
\hline Mxo. José Patricio Tagle & $\begin{array}{l}\text { Cura Rector Interino de la ciudad de La Rioja y Vicario } \\
\text { foráneo interino de la misma ciudad }\end{array}$ & 1800 \\
\hline
\end{tabular}

${ }^{43}$ La mayoría de estos datos fueron obtenidos de los legajos de ordenación. AAC, Leg. 24 Tomos II al VI.

${ }^{44}$ Datos tomados de los legajos de concursos. AAC, Leg. 25, Tomos III y IV.

* Tío de Julián Carmona. 
Pese a que esta tabla presenta una foto en la vida de estos hombres nos permite ver una característica que se desprende del estudio de sus trayectorias a partir de sus fojas de meritos y servicios. En general se movieron en un espacio geográfico y social que excediendo la jurisdicción riojana parece marcar los limites de un verdadero espacio social, y tal vez también económico, representado por los pueblos colindantes a la Rioja como Ancasti, Tinogasta o Piedra Blanca. Esta característica podría indicarnos la importancia que otros espacios diocesanos, que no eran las ciudades, tendrían para las carreras de los clérigos ${ }^{45}$.

\section{COLORES LOCALES}

La lógica del funcionamiento colonial en la que «los tejidos sociales del negocio y la política se confundían... en una única trama de relaciones personales» ${ }^{46}$ cobran nitidez en algunas prácticas vinculadas a los concursos.

Recién llegado al Río de la Plata, el Virrey Marqués de Avilés (1799-1801) decía estar sorprendido por haber escuchado que eran prácticas usuales en esa jurisdicción las «quotas fixas de pesos en plata, ù onzas de oro, o cajas del mismo metal qe se piden, o se reciven de los curas provistos, ya con el titulo de albricias por los que exercen el vice Patronato Real al llevarse la nomina de su promocion, ó yá con titulo de obsequio o regalo, ó agradeciemiento al tiempo de sacar de ellos la Prestación Real, llegando al extremo de querer entablar estas corruptelas con el nombre de legitimos dxos, tarifas, o regalias inseparables del Vice Patronato Real» ${ }^{47}$. Aunque esta costumbre es denunciada por Avilés como una muestra escandalosa de simonía, estas prácticas parecen antiguas y universales ya que le propio Concilio de Trento llamaba la atención acera de ellas condenándolas ${ }^{48}$.

\footnotetext{
${ }^{45}$ En un trabajo anterior habíamos mostrado como las parroquias situadas en «... lugares vecinos a los tres circuitos mercantiles entre los cuales el más importante, por su giro, era el de Buenos AiresPerú, parecían los más codiciados» Cf. Gabriela Caretta-Valentina Ayrolo «Clérigos seculares del Tucumán entre la colonia y la independencia (1776-1810)» Aguirre, Rodolfo y Enríquez, Lucrecia (coordinadores), La iglesia Hispanoamericana de la colonia a la república, México, Editorial Plaza y Valdés, Ediciones Universidad Católica, 2008, en prensa.

46 «La trama que organizaba la acción política unía unos actores sociales con otros por lazos recíprocos del crédito y la deuda propios de la medicación. O sea favores a cambio de cambio de apoyo político y otros favores con los cuales satisfacer nuevas demandas ...» Zacarías MouTOUKIAS, «Gobierno y sociedad en el Tucumán y el Río de la Plata, 1550-1800» en Nueva Historia Argentina. Tomo 2 Enrique TANDETER (dir) «La sociedad colonial». Buenos Aires, Sudamericana, 2000, p. 395.

${ }^{47}$ Edicto del 26 de abril de 1800, AAC, Leg. 25 T. III. La cursiva es mía.

48 Dice el Concilio de Trento, sesión XXIV, canon 18 de reformatione. Capítulo XVIII: «Guárdense también de recibir absolutamente cosa alguna con motivo del examen, ni antes ni después de él: y a no hacerlo así, incurran en el crimen de simonía tanto ellos como los que les regalan, y no puedan ser absueltos de ella, si no hacen dimisión de los beneficios que de cualquier modo obtenían aun antes de esto; quedando inhábiles para obtener otros después ...».
}

Hispania Sacra, LX

122, julio-diciembre 2008, 659-681, ISSN: 0018-215-X 
Si bien no hemos encontrado referencias a la utilización de este mecanismo específicamente en el ámbito de los concursos eclesiásticos si conocemos su existencia para otros espacios como los del cabildo de la ciudad de Córdoba ${ }^{49}$. Por tanto, no sería raro tropezar en algún momento con denuncias de este tipo, sobre todo considerando como lo haremos enseguida, la circulación intra élite de favores.

Desde épocas coloniales, en Córdoba los asuntos domésticos, las cuestiones sociales y de la política se entrelazaban de forma tal que la tensión era permanente. Con la llegada de nuevos funcionarios a la jurisdicción estas tensiones se avivaban al compás de los esfuerzos desplegados por cada facción por cooptar a los recién llegados. Esto ocurrió cuando el flamante intendente, Marqués de Sobremonte, tocó suelo cordobés en 1784. Resabio de aquellas diferencias entre «funistas» $\mathrm{y}$ «sobremontistas» ${ }^{50}$, fue el pleito desatado con motivo de la confección de la terna para el cargo de sacristán mayor de la catedral, concursada en $1805^{51}$.

Por muerte del obispo Ángel M. Moscoso, el concurso había quedado en manos del Vicario Gregorio Funes. Los candidatos ternados para ocupar la sacristía mayor de la catedral fueron: Dr. ${ }^{n}$. Felipe Funes ${ }^{52}$, Lic. D ${ }^{n}$. Benito Lasca$n^{53}$ y D $^{\text {n. Justo Barrera }}{ }^{54}$, Hecha la terna se la envió al virrey y vice-patrono, Rafael de Sobremonte, quien al recibir los papeles del concurso escribe una carta al vicario Funes. En ella objeta el orden y le solicita que lo modifique porque excluía «absolutam ${ }^{\text {te }}$ de la terna al $\mathrm{D}^{\mathrm{r}}$ Dn Pedro Vic $c^{\text {te }}$ Ferreira, q que cuenta $^{\mathrm{e}}$ veinticuatro años de cura delos Anexos de esa ciudad» ${ }^{55}$. El expediente rechazado vuelve a Córdoba y comienza el descargo.

En su defensa de la resolución del expediente, el deán Funes señala que antes de realizarse el concurso, Ferreyra ya se creía dueño del beneficio figurándose ya su titular había solicitado a los presbíteros Celestino Millán y Teodoro Lozano que lo excusaran alternativamente en la sacristía, para que él pudiese descansar en su residencia rural.

En el alegato, Millán y Lozano confirmaron los dichos de Funes de forma tal que el expediente se concentró en justificar los motivos que explicaban la desa-

\footnotetext{
49 Denuncia de 1807, en AMC, Libro de sesiones n $\mathrm{n}^{\circ} 43-44$.

${ }^{50}$ Los llamados «funistas» respondían a la casa de los hermanos Ambrosio, Gregorio y Domingo Funes y los «sobremontistas» reunían a los partidarios de los hermanos Victorino y Juan Justo Rodríguez y claro de Sobremeonte.

${ }^{51}$ Todos los documentos citados en este apartado son de: AAC, Leg. 25 T. III

52 Hijo de Ambrosio Funes, sobrino de Gregorio y «clérigo de menores ordenes de edad de veinte y seis años $(\ldots) \gg$

${ }^{53}$ El futuro obispo de Córdoba en aquel entonces: «clerigo presbítero y de igual edad» que Funes.

54 «Clerigo presbitero qe apenas hà estudiado Gramatica y los primeros años de filosofia»

${ }^{55}$ Carta del Virrey a Funes fechada en Buenos Aires el 27 de abril de 1805. Vale la pena aclarar que en las listas de admitidos a los concursos de 1804, Ferreira no aparece aunque si está en la del 1800.
} 
tención al pedido del virrey. Pese a que las numerosas páginas dedicadas a este asunto interesan para observar muchas cuestiones de la vida cordobesa, en esta oportunidad sólo nos detendremos en los motivos esgrimidos por los examinadores sinodales para establecer el orden de la terna. Estas razones nos interesan porque se vinculan al perfil «delineado» para el cargo de sacristán y a como este se construía al calor de la vida local.

De acuerdo con los examinadores sinodales el candidato debía ser: digno, joven y virtuoso.

Según Fray José Leiva «... Sto Thomas, Soto, Cobarrubias, Murillo, Gutiérrez, y generalmente todos los autores dicen $\mathrm{q}^{\mathrm{e}}$ no se hade entender $\mathrm{p}^{\mathrm{r}}$ mas digno el mas $\mathrm{S}^{\text {to }}$ ni el mas docto, ni el de más servicios, sino aquel más apto y util $\mathrm{p}^{\mathrm{a}}$ el Beneficio aqe sele destina» ¿Cómo definen dicha aptitud y utilidad?, ¿cómo se establece la «idoneidad» para ocupar el cargo de Sacristán?, ¿quién es apto entre los discutidos eclesiásticos y por qué? Digamos primero que la instrucción parece ser una cuestión necesaria pero no determinante. Lo que se entiende decisivo para ocupar el beneficio, era la dignidad. Condición resumida en: «aquellas proposiciones, que exige su naturaleza para su exacto cumplimiento» ${ }^{56}$.

En este sentido la juventud de Funes y de Barrera, en contrapartida con la avanzada edad de Ferreyra fueron considerados elementos favorables sobre todo porque se consideraba necesaria una «salud robusta» para la atención de la sacristía: «pues siendo este oficio sumamente laborioso, que pide una vigilante actividad para el servicio de los señores de este Coro en sus funciones de Catedral, y al mismo tiempo para aiudar à los curas en la administración de Sacramentos, sin reservarse horas del dia, ni de la noche, una asidua asistencia à la iglesia (...) $\rangle^{57}$. Además se alega que es poca cosa la sacristía para un eclesiástico de la experiencia de Ferreyra ya que este lugar por derecho canónico puede ser ocupado por un simple minorista, que es el caso de Funes, y desde los 14 años.

Pero volviendo al perfil del sacristán además de «instrucción, juicio y probidad de costumbres» ${ }^{58}$, «virtud y exemplar vida» ${ }^{59} \ll$ piedad y religión» ${ }^{60}$, «jui-

\footnotetext{
56 «... aquellas qualidades, y circunstancias, que hacen al sujeto más à propósito pa su mejor servicio, y desempeño, y que no consiste solamente ni en la mejor literatura, ni en la maior virtud, ni en la antigüedad del orden, ni mas años de servicio, sino que, considerada la calidad del beneficio, deben solicitarse «aquellas proposiciones, que exige su naturaleza para su exacto cumplimiento» parecer de José M. de Castro.

${ }^{57}$ Parecer del examinador Miguel de Castro coincidente con el resto de las declaraciones. Fray Elías del Carmen agrega que de ese empleo «depende la seriedad, religioso culto y magnificencia, con que en la Cathedral principalmente se deben desempeñar las funciones del culto debido al todo Poderoso ...»

${ }^{58}$ Fray Elías del Carmen, sobre F. Funes.

59 Ídem.

60 Ídem.
}

Hispania Sacra, LX

122, julio-diciembre 2008, 659-681, ISSN: 0018-215-X 
ciosa conducta por su recogimiento», «modestia» «frecuente asistencia a las funciones eclesiásticas, y demás exercicios de piedad ...» ${ }^{61}$, «singular contracción al ministerio, por la prolijidad en el aseo de la Iglesia, por el escrupuloso cuidado conque procura mantener los utensilios, y vasos sagrados» ${ }^{62}$, «recogimiento austero» ${ }^{63}$, «humildad y dulzura» ${ }^{64}$, otro elemento distingue a Felipe Funes y explica su posicionamiento en la terna era: «... ser hijo de un insigne Benefactor de la Iglesia, e individuo de una familia $q^{\text {e }}$ es mas conocida por su piedad y servicios hechos a la Iglesia, qe ninguna otra» ${ }^{65}$ y agrega Fray Elías de Carmen, «... la Iglesia mira con mucha especialidad el agradecimiento à sus bienechores, y pone entre las causas $\mathrm{q}^{\mathrm{e}}$ faciliten dispensas siertas se hacen con los bienechores, como entre muchos otros canonistas lo serian Fagnano y Pignatelli, quienes citan las decisiones de Roma sobre este particular». Así, respaldada canónicamente, la terna parecía indiscutible.

Los dictámenes de los examinadores fueron acompañados del descargo del Provisor del obispado Gregorio Funes quien por todo lo antedicho se negaba a cambiar la elección realizada arguyendo él también, mediante citas de autoridades en la materia, que por la naturaleza espiritual del cargo correspondía la decisión a la curia y pese a la condición de vice-patrono de Sobremnonte, éste no podía intervenir. Además señalaba sus discrepancias con aquel que, desde la «clandestinidad» 66 y disimulado bajo la denominación de «Rev. do Teólogo», estaba informando al virrey ya que, según dice Funes, rivalidades «tan sabidas en este Pueblo como injustas, no son de naturaleza». Posiblemente quien se escondía detrás de la figura de «Rev.do Teólogo», haya sido Juan Justo Rodríguez amigo de Sobremonte, pero además primo lejano de Ferreira. Pese a todo, la resolución del asunto no benefició a Felipe Funes ${ }^{67}$, ni a Ferreira.

\footnotetext{
${ }^{61}$ Miguel de Castro sobre F. Funes.

62 Miguel de Castro sobre J. Barrera.

${ }^{63}$ Domingo Leiva sobre F. Funes.

64 Domingo Leiva sobre J. Barrera.

65 Domingo Leiva sobre Felipe Funes. Dice Castro sobre el mismo tema: «sus Padres, movidos de solo su piedad, y devoción en que habra tenido mucha parte la del hijo, se han esmerado en decorarla, contribuiendo generosamente con sus facultades à la construcción de los altares del corazón de Jesús, y de Nxa Señora de Nieva, y donando liberalmente sinco cálices, y patenas de plata dorados de que usa la Iglesia en los días de maior solemnidad». Dijo Elías del Carmen «ser hijo de un particular bienechor desta Iglesia Cathedral, esto lo saben todos, pues son mui notorias las larguesas de Dn. Ambrosio Funes para la Iglesia Cathedral ...»

66 Nuevamente aparece la figura de los informes reservados como importantes para definir concursos.

${ }^{67}$ Luego de este conflicto Felipe Funes decidió partir al Alto Perú a donde le se libraron dimisorias para su ordenación sacerdotal en 1808. Recordemos que al momento del concurso por la Sacristía Funes solo tenia las ordenes menores. El 3 de octubre de 1808 «Se le libraron dimisorias al Dr. Dn. José Felipe Funes para ser promovido a las sagradas ordenes mayores, del Diaconado, Subdiaconado y Presbiteriado por el Ilmo Sor Arzobispo de Charcas...» AAC: Leg. 24, T. II bis, Libro de Ordenes p. 116 v. En cuanto al destino de Felipe Funes puede verse la correspondencia entre el deán y su familia
} 
Gracias a este pleito pudimos observar varias cosas. Por un lado, la forma de selección de los candidatos y, por ende, cómo se iban definiendo los perfiles para cargos más prestigiosos como el de sacristán de la catedral. En este sentido vimos como se combinaban los candidatos existentes, con las conveniencias locales y características deseables. Por otro, cómo el peso de los desacuerdos, de las enemistadas pre-existentes y de las ambiciones personales, se manifestaba aún durante los concursos que habían sido pensados para que los beneficios vacantes se ocuparan con «párrocos dignos y capaces».

Este conflicto nos permite pensar el poder en términos relacionales ya que en casi todos los casos, y este no fue excepción, fue la calidad y cantidad de relaciones la que posibilitaba el éxito o no de una «empresa» de tipo personal ${ }^{68}$.

Si durante la colonia las rencillas internas fueron fuente de pleitos, objeciones y favores durante la época independiente un nuevo componente se sumará a estos: la obligación de demostrar colores «patriotas».

\section{LOS REQUERIMIENTOS}

Como se sabe, para tomar estado eclesiástico una de las condiciones necesarias era la limpieza de sangre. Este requisito fue muchas veces soslayado a favor de la ordenación de candidatos a los que se consideró aptos por haber sido apadrinados por personajes importantes o bien por su buena conducta, noble carácter, etc.

Mirando los expedientes del concurso de 1800 encontramos uno que refiere a haberse «controvertido y puesto en duda» la «legitimación» del Maestro Juan Nicolás de Luna por medio de:

... siniestros ynformes que se han expuesto ante el Sor. Obispo de donde ha resultado que su señoria ilustrisima con no pequeño pesar de su caritativo corazón ha escluydo al espresado delas funciones dela oposición con no poco desonor de su persona y estado $(\ldots)^{69}$.

El que toma la palabra y defiende los derechos de Luna es Juan Ángel de Herrera, quien había declarado ser el padre adoptivo de Juan Nicolás. Al momento de su ordenación Juan Nicolás es presentado por su padre adoptivo con

sobre todo las cartas de Sixto (hermano de Felipe) Funes con su tío Gregorio. Archivo General de la Nación (AGN) Biblioteca Nacional (BN) correspondencia epistolar de Funes n ${ }^{\circ} 3739$.

${ }_{68}$ Moutoukias señala que «el poder político no es una sustancia, ni una cualidad y menos aún un objeto, una práctica o un discurso. Se trata de una relación social» Zacarías MoutouKIAS, «Gobierno y sociedad en el Tucumán y el Río de la Plata.», op. cit. p. 408.

${ }^{69} \mathrm{AAC}$, Leg. $25 \mathrm{~T}$ IV.

Hispania Sacra, LX

122, julio-diciembre 2008, 659-681, ISSN: 0018-215-X 
los apellidos Herrera y Sotomayor (el de su mujer) ${ }^{70}$. Herrera señala que Juan Nicolás era «hijo natural en su concepción» y que fue expósito en su casa donde fue «proygado por mi y por mi esposa». Pese a las gestiones realizadas por Herrera Juan Nicolás no concursa.

Las declaraciones de los testigos que lleva el interesado coinciden en señalar que Juan Nicolás:

... hera de noble y legitimo nacimiento de padres conocidos y que como estos fueron pobres no pudieron dar a los hijos aquella educacion civil que correspondia a la distincion con que nacieron; y caso el diho Don Francisco [padre de Nicolás] en familia que llaman Bazanes, de gente humilde y buena, y no save si después de haver tenido algun hijo, antes de solteros (...).

Otro declarante dijo que los Herrera, con «sus desvelos y alimentos lo han puesto en el Estado del sacerdocio» y hasta expone la supuesta madre biológica de Juan Nicolás, quien dice que tuvo al niño antes de casarse y que luego pensaba recuperarlo pero cuando quiso hacerlo Herrera se resistió «echando por empeño al Sor Canónigo del Moral -en el momento de la declaración arcediano de la catedral de Córdoba- que fue cura y vicario de esta ciudad en aquel entonces prometiendoles hazerlo estudiar y tambien hazerlo heredar como asi lo ha cumplido el dicho Dn. Juan Ang ${ }_{\gg} 71$.

Este expediente permite acercarnos a una cuestión que parece haber sido eludida en otros casos, ya que no sería creíble que este caso fuese el único en su tipo. Por eso llamamos la atención acerca de un tema sobre el que es poco y nada lo que sabemos: el ingreso al clero secular de candidatos de sectores desprotegidos socialmente, que podrían «esconder» e incluir mestizos y castas, gracias a figuras socialmente prominentes ${ }^{72}$.

\footnotetext{
${ }^{70}$ En el expediente de ordenación de Juan Nicolás Herrera / de Luna, figura su partida de bautismo que dice: «En la ciudad de la Rioja en once días del mes de octubre de mil setecientos y setenta años: en la Iglesia matriz bautice, puse oleo y chrisma a Juan Nicolás de padres no conocidos, que lo crían en cassa de Don Juan Angel de Herrar, fueron sus padrinos el dicho y su esposa Doña María Dominga Sotomayor, y para que conste = Maestro Miguel del Moral» AAC, Leg. 24, T.III y 24, TII bis, año 1793 figura dispenda «en el defecto de Natales». Es importante señalar que en el expediente seguido en 1800 se identifica a los padres de Juan Nicolás, sin embargo según lo habían decretado los obispos del Tucumán a mediados del siglo XVIII, «... si la criatura que se bautiza no fuese de legítimos matrimonio, aunque se sepa su padre o su madre, se dirá hijo o hija de padres no conocidos para estorbar la infamia de sus padres (...)» Cf. La normativa en Mónica GHIRARDI, Matrimonios y familias en Córdoba 17001850. Córdoba, Ferreyra ed, 2004, p. 521.

${ }^{71}$ AAC, Leg. 25 T. IV.

72 Pienso, que para el caso de la Rioja también podría tratarse de indios acriollados al ingresar a familias de las elites locales por vía de «padres desconocidos», pero son solo «ideas» sobre las que hay que trabajar. Para Salta se puede consultar Gabriela, CARETTA «'se habían vestido de hábitos clericales'. La inclinación al estado como construcción social de la vocación», Ponencia presentada en las Primeras Jornadas de Historia Social, La Falda, Córdoba, 2007.
} 
En orden a las limitaciones y/o requerimientos solicitados a la hora de presentarse a concursar importa advertir que, a partir de la Revolución de mayo de 1810, comenzó a definirse un nuevo lugar para la religión, lo que traerá aparejadas modificaciones muy significativas en el orden interior eclesial ${ }^{73}$. La Asamblea del año XIII (1813) $)^{74}$, pródiga en legislaciones establece «una corrección» en los llamados a concurso anunciando que los opositores a curatos, además de presentar sus méritos y servicios deberían demostrar su calidad de patriotas por considerar que esto:

... mas que una conveniencia, ès un deber, $\mathrm{p}^{\mathrm{r}}$ que asi lo ha dispuesto la A.G.C en 27 de julio último; y $\mathrm{p}^{\mathrm{r}}$ que los curas $\mathrm{p}^{\mathrm{r}}$ la parte que tienen en la direccion de la suerte de la $\mathrm{Pa}$ tria, en razón de su activa influencia en la conducta de los hombres, deben antes justificar, $\mathrm{p}^{\mathrm{a}}$ serlo, si tambien han llenado y desempeñan las obligaciones de hombre y ciudadano de el Estado, de $\mathrm{q}^{\mathrm{n}}$ constantemente reciben su protección ${ }^{75}$.

El primer concurso que en Córdoba deberá respetar el decreto de la Asamblea del XIII es el 1814 convocado por el obispo Rodrigo A. de Orellana. Como se recordará, apenas pasado el concurso el Obispo es confinado por refractario y antipatriota, al convento franciscano de San Lorenzo, provincia de Santa Fe, y las ternas quedan sin elevarse ${ }^{76}$.

La elección por parte del poder político de un nuevo vicario y gobernador del obispado en la persona de Juan Francisco de Castro y Careaga trajo bastantes problemas ${ }^{77}$. Mientras Orellana se dirigía desterrado a Santa Fe, Castro y Careaga subía hacia Córdoba. No hubo mayor contacto entre ellos. Las faculta-

${ }^{73}$ Sobre la administración de las cosas eclesiásticas en uso del patronato se puede ver: «Argumentos y prácticas patronales durante la experiencia de la centralidad política en las Provincias Unidas, 1810-1821» Anuario, Centro de Estudios Históricos «Profesor Carlos S.A. Segreti», 4, Córdoba, 2004, pp. 107-122.

${ }^{74}$ La Asamblea general constituyente del año 1813 asumió, según reza su 1er. Articulo, «la representación y ejercicio de la soberanía de las Provincias Unidas del Río de la Plata»organizando y legislado su vida administrativa y política. Sobre el periodo se puede consultar Noemí GoldMAN, (Comp.) Revolución, República, Confederación (1806-1852). Nueva historia argentina, Tomo III, Buenos Aires, Sudamericana, 1999. Vale la pena resaltar que el mismo proceso se vivirá en otros espacios como el Perú. Sobre el particular ver Ernesto, RoJAS INGUNZA El báculo y la espada. El obsipo Goyeneche y la Iglesia ante la «iniciación de la República» Perú, 1825-1841. Lima, Fundación Bustamante de la Fuente-Instituto Riva-Agüero, 2006, p. 77.

${ }^{75}$ Correspondencia del 10 de diciembre de 1813, por: José de Ugarteche - Antonio A. de Jonte Justo José Núñez (secretario) AAC, Leg.. 25 T. IV.

${ }^{76}$ Cf. Cayetano Bruno, El obispo Orellana y la revolución. Córdoba, Junta de Provincial de Historia de Córdoba, 1981.

${ }^{77}$ La conducta del nuevo Vicario también fu conflictiva en su diócesis de origen, ver María Elena BARRAL, De sotanas por las Pampas. Religión y sociedad en el Buenos Aires rural tardo colonial. Buenos Aires, Prometeo, 2007, pp. 51-64, y su trabajo: « $i$ 'Voces vagas e infundadas'? Los vecinos de Pilar y el ejercicio del ministerio parroquial, a fines del siglo XVIII.» en Sociedad y Religión., $\mathrm{N}^{\circ} 20-$ 21, 2000, CEIL-PIETTE/CONICET, pp. 71-106.

Hispania Sacra, LX

122, julio-diciembre 2008, 659-681, ISSN: 0018-215-X 
des que le fueron acordadas a Careaga fueron las mínimas para gobernar la diócesis y esto desconcertó y disgustó al nuevo vicario ${ }^{78}$. Además, cuando el nuevo provisor llegó de Buenos Aires el Obispo ya había designado a José María Bedoya para cubrir esa función ${ }^{79}$. Con todo, Bedoya se hizo a un lado y Carega tomó posesión de su cargo.

Lo primero que pretende hacer el nuevo Vicario es confeccionar las ternas del concurso pasado, pero se encuentra sin facultades para hacerlo. El obispo no le había «entregado» la jurisdicción necesaria. Sin embargo, el 14 de febrero de 1815 le escribía diciéndole que le había concedido las facultades extraordinarias denominadas «sólitas» ${ }^{80}$, «suponiendo -dice Orellana- que Ud. formaría las ternas para los curatos y arreglaría lo demás concerniente al concurso» ${ }^{81}$. Animado por esta comunicación, Careaga confecciona las ternas ${ }^{82}$. La repercusión fue inmediata. Enseguida comenzaron a circular rumores sobre la ilegalidad de las funciones del nuevo Vicario para armarlas. Originándose un «Expediente contra los que opinaban de nulidad de concurso» ${ }^{83}$ que sirvió sobre todo para cuestionar a un numero importante de eclesiásticos reputados de refractarios al sistema.

Si bien casi todos los implicados tuvieron que demostrar su carácter patriótico, otros que no se habían pronunciado abiertamente en contra del Provisor hicieron uso de excusas más sutiles para no obedecer. Ese es el caso de José Saturnino Allende que había sido ubicado en primer lugar en las ternas de: Pocho, Santa Rosa, Río Seco, Ischilín y Río Tercero Abajo, y que «renunció a todo derecho» aduciendo su ordenación a titulo de patrimonio ${ }^{84}$.

Sin embargo, sería arbitrario decir que los argumentos de tipo político sólo fueron válidos con el advenimiento de la Revolución. Ya que este mismo tipo de evidencias se usaron para definir un buen clérigo durante la colonia. Así lo deja ver el legajo de méritos y servicios, que en 1800, presentó a concurso el Maestro Pedro Ignacio Arce. Allí puede leerse «y en el 1782 sosegó con sus exhorta-

${ }^{78}$ Cf. Cayetano BRUno, El obispo Orellana y la revolución... op. cit. p. 334.

${ }^{79}$ Sobre este conflicto se puede consultar nuestro trabajo Valentina AYrolo Funcionarios de Dios y de la Republica... op. cit. Pp. 66 y 67 especialmente.

80 «...absuelven sin ninguna restricción de toda clase de reservados i aun delegan a su arbitrio, esa facultad, cuando lo creen necesario o conveniente». Justo Donoso, Diccionario teolojico, Canónico, juridico, liturjico, biblico etc. Valparaíso, Imprenta \& Librería El Mercurio, 1856, p. 303.

${ }^{81}$ Cayetano BRuno, El obispo Orellana y la revolución... op. cit. p. 336.

${ }^{82}$ El 29 de enero de 1791, un auto acordado de la Cámara de Castilla, encargó al vicario capitular y no al cabildo, de redactar y expedir las ternas de provisión de curas. La resolución de Carlos IV en consulta de 26 de mayo de 1800, publicada por Carta Circular de 1 de julio, estipuló que el vicario capitular y no el cabildo, fijase la fecha del concurso a curatos. Ch. Hermann, L'Eglise d'Espagne sous le patronage royal ...op. cit. pp. 263-270.

${ }^{83}$ AAC, Leg. 37, T. V.

${ }^{84}$ Ternas en AAC, Leg. 25 T. IV. 
ciones el fuego de la revolución, $\mathrm{q}^{\mathrm{e}}$ comenzaba a encenderse en la jurisd $\mathrm{n}^{\mathrm{n}}$ de Catamarca» $\mathrm{y}$ «Dono 40 pesos fuertes a la corona por p $\mathrm{p}^{\text {ra }}$ guerra y ofrecio 150 mas al siguiente año y «siento en cada año de los qe dure la guerra» ${ }^{85}$. Así muy probablemente lo que ocurre después de la Revolución es que se cambia la causa de fidelidad pero no, la forma requerida de demostrarla ${ }^{86}$.

\section{OBSERVACIONES FINALES}

Como hemos podido observar los expedientes reunidos en este fondo proporcionan buenas pistas sobre múltiples temas. Los perfiles eclesiásticos, de clérigos y obispos, la organización beneficial, el alcance del poder de obispos y vice-patronos, la lógica política facciosa de las sociedades locales, ya sea la de la cabecera del obispado como así también la de los lugares de origen de los candidatos, arista que no hemos explorado aquí pero que manifiestan los expedientes consultados, entre muchos otros.

En lo relativo a los concursos Manuel Riego dice que los exámenes junto a las conferencias morales «fueron un auténtico vehículo y medio para la formación permanente del clero» ${ }^{87}$. Si bien no estamos en condiciones de aseverar que ese haya sido el efecto para la diócesis del Tucumán, podemos llegar a algunas conclusiones.

En primer lugar, el hecho de tener que preparar un expediente en donde constasen méritos y servicios, lo que significaba mostrar públicamente una trayectoria «profesional», debe haber obligado a los clérigos a considerar su capacitación personal como un tarea importante. Sin duda, esto influyó en el «reconocimiento» $\mathrm{y}$ «preparación de un perfil» adecuado a las funciones clericales.

La pobrísima formación del clero riojano, fue notada con alarma por el obispo Orellana quién, en visita a La Rioja en 1813 y luego de haber examinando el estado de la Iglesia local había advertido la falta de libros adecuados a la «formación permanente» del clero. Así, atendiendo a la imagen personal de la formación que debía tener un clérigo, y habiendo escuchando estas necesidades de boca de los propios eclesiásticos, estableció «Conferencias de Moral y Sagrada liturgia (...) sobre el estado sacerdotal y particularmente los del confesio-

\footnotetext{
${ }^{85}$ Meritos y Servicios de P. I Arce. AAC, Leg. 25 T. III.

${ }^{86} \mathrm{La}$ intervención del poder político puede haber jugado a favor de Fermín de la Colina, quien «A propuesta del Cabildo de aquella ciudad le nombró el Sup.mo poder Ejecutivo a 7 de abril de 1812 por catedrático de Filosofía de ella», y tal vez, para ubicarlo en tercer lugar una de las controvertidas ternas, la del curato de Ischilín, confeccionada por el provisor Castro y Careaga el 10 de octubre de 1815. AAC. Leg. 25. T. IV (Ternas)

${ }^{87}$ Manuel M., Riego Los concursos a parroquias... op. cit. p. 19.
} 
nario» nombrando a Pedro Antonio de la Colina para impartirlas en calidad de examinador sinodal ${ }^{88}$. De esta forma, hubieron algunos movimientos tendientes a nivelar al clero local según un «deber ser» pero atendiendo la propia medida.

Vinculado a este punto podemos presumir que el origen y la preparación de los obispos también influyeron en las exigencias y expectativas puestas en el clero diocesano, como aparece en los concursos. Seguramente cada uno de ellos tenía en mente una imagen de lo que debía ser el clero de su diócesis. Sobre la forma en que cada obispo pensó, organizó y administró el espacio eclesiástico del Tucumán sabemos poquísimo y, pese ser muy interesante y valiosos y necesario, es un trabajo que resta hacer.

Posiblemente el obispo arequipeño Ángel M. Moscoso haya sido más contemplativo a la hora de componer los exámenes los que se recordará, por ejemplo, propuso en castellano. Y más exigente y más alta la expectativa de Rodrigo A. de Orellana que, no sólo venía de otra realidad, sino que además tenia altas calificaciones ${ }^{89}$.

Por medio de este análisis hemos podido comprobar también, nuevamente, las dificultades de Trento para alcanzar estas regiones. Muchas de las pautas que se exigieron en el decreto De reformatione no se cumplían, porque no se quería pero muchas veces porque no se podía. Son éstas las que van a dar forma a una Iglesia con tintes claramente locales.

Por ultimo, los concursos, en tanto instrumentos claramente canónicos, ciertamente ayudaron a concretar un clero más instruido y disciplinado. Operando como seleccionadores de párrocos «dignos», un concepto cuyo contenido irá variado según la época, para las parroquias en tanto espacios por excelencia de la mediación social. En este sentido podría pensarse que podrían haber jugado un rol importante a la hora de profesionalizar el estado eclesiástico. Este aspecto implicará un lenta especialización y con ella una progresiva separación de las esfera política-estatal y de la religiosa, ambas como espacios en construcción en las Provincias Unidas.

\footnotetext{
${ }^{88}$ Este clérigo, tenía una formación superior al resto. Recordemos que es el único que tiene dos diplomas y su examen es el más detallado y documentado de todos los presentados en 1800. Cf. AAC. Leg. 25. T. IV, año 1813.

89 Diremos resumidamente que fue profesor de instituciones teológicas, cátedra que obtuvo por oposición en 1785, y entre 1786-1788 había ejercido el cargo de Conciliario de la Universidad y académicos de la real academia de jurisprudencia practica de la Universidad. Además era Individuo honorario de la academia de Matemáticas. La trayectoria profesional y académica de Orellana puede consultase en Cayetano Bruno, El Obispo Orellana y la revolución... op. cit.
} 